\title{
Vulture updates No 09 - September 2018 - Around the World of Vultures \& VSG activities
}

This biannual newsletter of the IUCN Vulture Specialist Group mainly features updates by region but also mentions developments of VSG and we are aware that we still need to do much more. We now have the CMS Multi-Species Action plan (MsAP) (download this important resource for old world vultures if you haven't done so already), but the challenge to implement and coordinate the agreed actions remains as great as ever. VSG was approached regarding IUCN Green listing, and Eurasian griffon and Bearded vulture are being tested in some detail for possible qualification in a European context.

A total of 110 organisations registered activities for International Vulture Awareness Day (IVAD) 2018, from 26 different countries across five continents. The broad range of organisations included conservation organisations, universities, nature reserves, state parks, wildlife parks, zoos and museums. Countries with the highest number of participating organisations were the USA, India, Nepal, UK and South Africa. Armenia, Mexico, Socotra and Sri Lanka participants signed up for the first time. We are working with partners to better understand the potential impact of IVAD, and working to increase the reach and extent of IVAD activities, and for example we are aware that many unregistered organisations actively participate in IVAD -which is wonderful, but let's see if we can make even more of this increasingly popular annual focus.
We are very pleased to welcome Keith Bildstein as our Regional Co-chair for North America, and we would like to thank Masumi Gudka who steps down from that role for Africa.

\section{Africa Round-up}

The Raptor Research Foundation Conference in the Kruger National Park, South Africa 12-16 ${ }^{\text {th }}$ Nov 2018 included 25 vulture presentations and sessions on raptor tagging and tracking best practice. A $2^{\text {nd }}$ workshop with a wide participation "Towards the Conservation of African vultures" was held at the Socioeconomic Synthesis Centre, Univ. of Maryland, USA in May and a $3^{\text {rd }}$ workshop will be conducted (and reported) in Oct 2018.

$1^{\text {st }}$ Aug 2018, the South African Department of Environmental Affairs hosted an initial stakeholder meeting in Pretoria to draft a National Vulture Conservation Action Plan (NVCAP) for South Africa - a first step to implementing the CMS Vulture MsAP which will hopefully be replicated in other southern African countries and elsewhere. The bi-annual Bearded Vulture task Force meeting was held in Barkly East, Eastern Cape Province which reviewed and finalised the Bearded Vulture Biodiversity Management Plan.

A repeat survey after 20 years, driving 20,000 km across Botswana confirmed declines of eagles and vultures of up to $80 \%$. Whiteheaded and Lappet-faced Vultures showed the sharpest declines. Raptors Botswana provided 
bones to nesting Cape Vultures in the Tshwapong Hills region where wing deformities due to lack of calcium have been documented. Two students completed their Masters studies on White-backed and Cape Vultures. A third student just submitted a $\mathrm{PhD}$ on Lappet-faced Vultures. 14 Satellite tracking devices on Lappet-faced, Hooded, Cape and White-headed Vultures are showing movements between Botswana, South Africa, Zambia and Namibia. Raptors Botswana with Kanabo Conservation Link, have taken hundreds of adults and children to the CL Woolcott vulture restaurant in Ghanzi to view and learn about vultures. Work linking communities across the country with vultures has intensified, with new initiatives to be set up in SW Botswana. 'Sirri' an ambassador Lappetfaced Vulture has been very popular for this, visiting Ghanzi from Maun for IVAD. An aerial survey of the Gorongosa National Park in central Mozambique was partially surveyed for vulture nests 10-14 ${ }^{\text {th }}$ Aug 2018 - the first such survey for the country. Also TPF, with Boise State University expanded the sample of wingtagged and tracked vultures in the park to 46 birds between Jun-Aug 2018. Fieldwork in partnership with Birdwatch Zambia also doubled the number of tracked vultures in Zambia in late Aug 2018. Monthly monitoring of Hooded Vultures in Kampala, Uganda is ongoing, with roost counts yielding better results than counts at feeding sites. The current Kampala population is estimated at 200 birds, $56 \%$ being juveniles. It is now a year since two Hooded Vultures were tagged and although no new breeding sites emerged, the tracking work has identified several new feeding sites, which are in urgent need of protection.

Poisoning workshops were run in four southern African countries since April, led by the EWT-Hawk Conservancy Trust-University of Reading Partnership and reaching 234 participants. These include one with the Department of Wildlife \& National Parks, Raptors Botswana \& Birdlife Botswana. The Peregrine Fund (TPF) together with Living with Lions trained 30 community groups in Laikipia, Kenya in avoiding human-predator conflict, and recognising and containing poisoning incidents. Trainees already have already used this training to intervene and prevent the poisoning of two different lion prides and the team has now been requested to train county government workers and human health aides. Meanwhile nine more lions were poisoned in Serengeti, Tanzania, $31^{\text {st }}$ May - retaliatory poisoning after lions had killed two cows. At the same time, five of 10 vultures that were fitted with satellite transmitters in 2017 and 2018 in Masai Mara, Kenya, through the Preventing Poisoning to Save Africa's Vultures project implemented by a consortium (BirdLife International, Nature Kenya and Peregrine Fund and funded by the BAND Foundation), were in the Serengeti. This highlights the need for cross-border collaborations. The Kenya National Wildlife Poisoning Incidents Response Protocol was launched by the Chairman of the Kenya Wildlife Service (KWS) on $28^{\text {th }}$ June 2018. This protocol was developed collaboratively with conservation stakeholders and KWS provides guidelines to mitigate wildlife deaths and environmental contamination as a result of poisoning. This is supplemented by the establishment of a Poisoning Emergency Response Fund Initiative (PERFI) aimed at reducing the time taken to decontaminate a site, reducing risks of secondary poisoning. PEFRI outcomes could become a suitable framework of solutions for roll out across Africa.

The first Vulture Safe Zones (VSZ) in Africa have been set up in Zambia with over 250,000 hectares secured through outreach amongst farm 
managers and land owners. Focused on farm management practices, farmers and landowners in VSZs agree not to use poisons, follow guidance on appropriate use of chemicals and dispose of carcasses in designated areas with restricted access.

An ongoing Nangui Abrogoua University, Abidjan project in Comoé National Park ${ }_{2}$ NE Ivory Coast documenting vulture nests has demonstrated its regional importance for vultures in West Africa. Related student projects are underway on breeding success and the cultural role of vultures. In early 2018, more than $400 \mathrm{~km}$ of transects were carried out on foot. Outputs from these projects, supported by NABU have endorsed a Vulture Safe Zone approach for the area as prioritised in the MsAP.

In Morocco, Bearded Vulture was confirmed breeding still in the High Atlas after a gap in recent records. Also, one Egyptian (electrocuted), one Cinereous, one Eurasian Griffon and one Rüppell's Vulture were rehabilitated, tagged and released at Jbel Moussa National Park by the Moroccan wildlife conservation authorities and Moroccan Association for Falconry and Raptor Conservation Association (AMFCR).

\section{Asia Round-up}

Following on from the first six White-rumped Vultures in the terai of Nepal in Nov 2017, 12 more were released in September 2018 including eight of the first ever captive-bred birds (i.e. they were hatched in captivity at the Kasara Breeding Centre). Five of the six original released birds are alive and well ten months on, the $6^{\text {th }}$ was eaten by a predator, probably a leopard a month after release. Meanwhile, 20 wild birds have been tagged in the area and although all have ventured across the nearby Indian border, they mainly remain within a
$120 \mathrm{~km}$ radius. One adult however has wandered extensively in India to Shimla and all the way back again, but now has again gone beyond Shimla to Jammu and Kashmir. Further updates will be posted on SAVE news.

In India, hopes are growing that aceclofenac (a pro-drug of diclofenac which is gaining popularity, but which converts to diclofenac within the treated cow) may be restricted or banned in future: several state drug controllers have shown willingness to do this including Haryana and Uttar Pradesh, resulting from BNHS Vulture Safe Zone work in these areas. But the safety-testing programme of other drugs has not progressed significantly so far this year and nimesulide in particular is becoming more popular with some vets; among other drugs, nimesulide shows very worrying signs of being toxic to vultures. In the Sindh Province of Pakistan in June, the use of ketoprofen and aceclofenac was restricted around the main vulture colonies by the drug authority following letters and requests from WWF-Pakistan. It is hoped this welcome step will be a precursor for national level restrictions. Further meetings with government officials are planned this year with this objective in mind. In Bangladesh, pharmacy survey results in 2018 show that the regional ketoprofen bans in the two VSZs are starting to reduce ketoprofen availability (by $10 \%$ ), although it is still widely available as stocks are gradually being used up.

The Cambodia Vulture Working Group (specifically BirdLife Cambodia) received a grant from the Wildlife Reserves Singapore to continue anti-poisoning work and vulture surveys. It also formally approached the Government to ban veterinary diclofenac. A preliminary meeting was held in May in Myanmar, bringing together partners interested or involved in vulture work, and a follow-up meeting is planned and hosted at BANCA in 
Yangon in October 2018 to try to formalise a national vulture consortium, and agree and initiate further priority vulture work. This will also involve FFI, Friends of Wildlife, WCS, Government and others including RSPB and SAVE.

In China there have been several media reports in 2018 of vultures being hunted. In Xinhua, in one case, 23 Himalayan Vultures were hunted for food in Yunnan. In Qinghai, a Bearded Vulture was killed for 'medicine' apparently to treat stomach problems, and a Cinereous Vulture was reported being sold as a specimen. These cases are thought to be the tip of the iceberg, and there are certainly more going unreported.

\section{Middle East}

Oman seems to be a stronghold of the Egyptian Vulture, with many hundreds of birds often concentrating on Oman's waste treatment plants during winter - both local and wintering individuals - a new film on some research being made there, and more fascinating information appearing on movements of tagged birds from Oman into Iran and further north. While in Iran the Birds and Power Lines Committee has been working to minimise the threat of electrocution to vultures and other raptors. Finally, the important population of Egyptian Vulture in Socotra (Yemen) has attracted increasing attention locally, with some significant awareness work and their first IVAD events there.

Two key publications from 2018 were: Satellite tracking of a wide ranging endangered vulture species to target conservation actions in the Middle East and Horn of Africa. Biodiversity \& Conservation 27: 2293-2310 and Identifying critical migratory bottlenecks and high-use areas for an endangered migratory soaring bird across three continents. Journal of Avian Biology 49: $1-13$.

\section{European Round-up}

In late May the EU formally approved two updated international species actions plans: for Cinereous and Bearded Vultures, developed as part of a three year project, LIFE EuroSAP, led by BirdLife International. The Vulture MsAP approved in Oct. 2017 by the CMS - is still being promoted as the global blueprint for vulture conservation - like in this major conference organised by BirdLife International in Abu Dhabi.

Vulture population sizes and distribution trends are generally increasing in Europe unlike in other regions and this is often in response to conservation actions, which can be useful best practice for potential replication elsewhere. Bearded Vulture populations continue to increase - in the Alps 52 pairs (a new record!) raised 29 young and there was a significant expansion of their alpine range with a pair breeding for the first time in Écrins National Park (France). In Andalusia both breeding pairs were successful - the two chicks were even tagged in the nest by staff from the Junta de Andalusia. Both these populations originated from ongoing reintroduction projects. Thirteen Bearded Vultures have been released in different reintroduction projects in Europe, three in Baronnies, four in Andalusia, two in Maestrazgo, two in Switzerland and two in Austria. Further birds were also reintroduced in Picos de Europa (Spain). The release in the Maestrazgo was the first for this reintroduction project, that aims to connect the Andalusian with the Pyrenean populations.

With the increasing population in the Alps and Andalusia, Bearded vultures are also showing up in more countries - Portugal had its 
first record in 100 years, Holland was also visited by two birds, Greece had a rare mainland record, and some of the birds reintroduced in the French Massif Central move regularly to the Alps. Bearded Vultures in the Pyrenees are getting closer to the Massif Central, but unfortunately one Bearded Vulture - and a Griffon and a Cinereous Vulture - was poisoned to death in the Grands Causses in France. The species continues to capture the imagination of people and stakeholders, and many events and meetings gather hundreds of interested people. There were also some significant advances in the Bearded Vulture captive-breeding network like innovative surgeries being done successfully on birds, and a host of wild injured birds being successfully recovered with state-ofthe-art rehabilitation techniques. There was also a unique case of double clutching on this species

History was made with the first reintroduction of three captive-bred Cinereous Vultures into Bulgaria, as part of the Vulture Back to LIFE project. The birds fledged from their hacking platforms in August and are doing well. The team will transfer and release around 60 birds, some from captive-breeding, but mostly coming from wildlife rehabilitation centres in Extremadura (Spain) into the wild in Bulgaria as well as creating supplementary feeding stations, improving populations of wild herbivores, improving nesting conditions, creating artificial nest sites and tackling some of the major threats to vultures by insulating electricity pylons and addressing the illegal use of poison. The single Cinereous Vulture pair breeding in the Douro Canyon between Portugal and Spain - significant because it represents the longest natural recolonization known - bred successfully in 2018, in spite of another anxious breeding season: the nesting tree almost collapsed. Only successful hands-on management done at a critical moment saved this pair. Elsewhere, a scattering of unusual observations of Cinereous Vultures (like in Italy or in sub-Saharan Africa) attest to the increase of the species in Spain, Portugal and France. Last year's national survey in Spain, coordinated by SEO/BirdLife, indicated a breeding population of 2,500-3,000 pairs; an increase of almost $40 \%$ since 2006. In Portugal the population is also increasing, to around 15 breeding pairs, one of which was tagged in the nest by Portuguese conservation NGO LPN. Birds from the last Balkan colony in Dadia (Greece) are also roaming across the border to Bulgaria, so we hope that with the reintroduction ongoing there, and with the local conservation efforts to fix them in the Rhodopes, the species can also start to increase in the Balkans. One of the actions being done is to reinforce the local population of wild ungulates, as food availability can also be a limiting factor. A Cinereous Vulture found in Jordan was also successfully rehabilitated and tagged.

Egyptian Vulture is the only European species still with negative population trends particularly in the Balkans. A paper was published on the long-term (2005-2016) population trend, breeding performance and territory occupancy in Bulgaria. Supplementary feeding continues in Bulgaria and Greece, and two small supplementary feeding stations for Egyptian Vultures were established in Albania. The Balkan population of Egyptian Vultures is still declining rapidly and no information exists on the trend of the much larger adjacent population in western Turkey up to now. Counting of migrating raptors was established in September with three observation points covered north of the Gulf of Iskenderun in Turkey. Long-term data collected should allow monitoring of the majority of Egyptian Vultures and other birds of prey migrating around the 
eastern coast of the Mediterranean Sea. In September 2018, so far over 770 Egyptian Vultures were counted migrating through this bottleneck. Data are available online. Adult birds are however still being killed. Three of the five Egyptian vultures tagged in Douro are still transmitting and providing crucial data. Several captive-bred Egyptian Vultures were released in summer 2018: two in Italy, as part of a LIFE project on the species led by ISPRA, and seven in Bulgaria, as part of the new LIFE project on Egyptian Vulture, led by BSPB/BirdLife in Bulgaria. The two Italian birds died in Sicily (shot) and Tunisia (poisoned), while two of the seven birds released in Bulgaria migrated - the others were recaptured or are still in Europe. Two of these birds were released by hacking, four by delayed release, and one by fostering into a wild nest - a difficult operation that succeeded only at the second attempt. The Bulgarian pilot experimental programme had released three birds through the hacking method in 2016 and their movements can be followed online. At least 10 birds per method are expected to be released by 2022 in order to analyse which approach is the most efficient for the region to implement a future release programme. The Egyptian Vulture New LIFE project, together with the EAZA EEP led by Prague Zoo, started a programme for building a pool of captive birds with Balkan or genetically close origin. The aim is to set a breeding population in captivity which will produce enough offspring for release purposes in the Balkans in the future. One of the strongholds of this pool is the Green Balkans' Wildlife and Breeding Centre in Stara Zagora, where additional facilities have been built and Egyptian Vultures successfully bred in 2018. The centre currently holds 10 individuals.

In Sardinia 12 more Griffon Vultures were released in September to reinforce the small local population, as part of the successful Life Under Griffon Wings there. The first group of 14 griffons that had been released in April integrated perfectly into the Sardinian colony and regularly visit the two feeding sites established by the project and also the 17 small farm feeding stations set up with the farmers in the project area - setting an important precedent for Italy. Most of these griffons originate from rehabilitation centres in Spain. This species seems to be recovering slowly in the Balkans, where populations are still very much depleted breeding was good in 2018 in the Rhodopes, undoubtedly supported by the conservation work being done by the LIFE Re Vultures project. The $1000^{\text {th }}$ griffon was ringed in the nest by Croatian colleagues, whose work has been fundamental in the conservation of the species in the country, including the rehabilitation of many birds. With more griffons in Europe, and several of them tagged and marked, many roam across borders, and are seen by many people. Or the extreme case of a Bulgarian bird that was seen in France, proving beyond doubt that western and eastern populations are connected. Unfortunately, many still die in the Middle East, which seems to be a sink for many vulture species. Researchers also discovered for the first time nocturnal feeding of Griffon Vultures.

Poison baits - the single most widespread threat to vultures worldwide including Europe, where it continues to kill vultures - were highlighted by the Hellenic Ornithological Society which released a new study that documents the powerful impact of this threat on vultures. The most recent case of poisoning in Greece was detected in Agrafa Mountain in May 2018, based on intensive GPS/GPRS tracking of Griffon Vultures from Bulgaria. A dead bird with a transmitter was found about $7 \mathrm{~km}$ from a poison bait, and later two more poisoned Griffon Vultures were found at the site beside a calf 
carcass. An important finding was that some birds were found $20 \mathrm{~km}$ away and even up to 65 $\mathrm{km}$ from the poisoned bait they consumed - as in Kresna Gorge in Bulgaria in 2017 (see article in this volume). A significant new project was launched in the Balkans, covering Croatia, Bosnia \& Herzegovina, Albania, Macedonia and Greece, including the development of national anti-poisoning actions plans, funding for work on the ground, and a public awareness campaign. Several LIFE projects also have antipoisoning actions, while in Iberia the authorities, local governments and NGOs continue with their leadership in this area.

Diclofenac is still very much a potential threat in Europe - Spain and Italy still allow the drug to be sold, while in Portugal, disappointingly, a request for a legal permit is still being considered. Antibiotics are also being detected in vulture food, with potential negative impacts.

Collision with wind farms or other energy or ski infrastructure is also a significant cause of mortality, notably for Bearded Vultures (for example in Vanoise National Park (France), or for Cinereous Vultures in Greece). Regulation is very important, but solutions do exist - like the shut-on demand operation in some Portuguese windfarms.

Another threat to vultures that is increasingly on the European vulture agenda is lead poisoning, with efforts and lobbying being done to try to ban hunting with lead ammunition across all areas, and not only over wetlands. Vultures in Europe often feed on carrion from animals that have been killed with lead ammunition - and so any news that some areas important for vultures are banning lead ammunition - like a number of areas in Spain is obviously very welcome!

\section{North American Round-up}

Fieldwork on Turkey Vultures continues in Arizona USA, where Hawk Mountain Sanctuary recently placed satellite tracking devices on five birds west of Phoenix. This as-yet-to-be-tracked breeding population apparently does not feed on still-born livestock at dairy farms, unlike many other breeding populations in the state. Tracking of Black Vultures continues in Pennsylvania USA, near the northern edge of their breeding range.

Researchers from West Virginia University, the United States Geological Survey and other organisations are working on flight behaviour of California Condors to inform risks they may face from wind energy development. Four papers on condor movement have appeared over the past year and more are coming. Publications from the group include: Meteorological and environmental variables affect flight behaviour and decision-making of an obligate soaring birds, the California Condor Gymnogyps californianus. Ibis 160: 36-53; Lack of observed movement response to lead exposure of California Condors. Journal of Wildlife Management 82: 310-318; Improving estimation of flight altitude in wildlife telemetry studies. Journal of Applied Ecology 55: 2064-2070.

\section{South America Round-up}

In the last newsletter we reported the shocking news of 34 Andean condors carbofuranpoisoned in one incident, Jan 2018 in Mendoza, central Argentina. Unfortunately, new events occurred, luckily including fewer individuals. Eight condors were received for rehabilitation this year so far with fractured bone, lead poisoning and other unspecified health problems. Human wildlife conflicts are increasing in many areas, which may lead to 
direct or indirect (mainly poison baits) due to alleged attacks of newborn and young persecution with consequences for scavengers, through the targeting of carnivores that are increasing in some areas. More than 60 scientists from all over the world called on the Argentine president and Ministers to ban pesticides such as carbofuran, used to poison wildlife. A project to ban it was presented at the Argentine Congress, but no serious advances were obtained yet. Regarding Black vultures, a recent study done in Argentine Patagonia suggests that their use of rubbish dumps may increase their body size, but negatively affect their health. A recent BSc thesis from the University of Buenos Aires investigated humanpredator conflict in northern Argentina and found that the Andean Condor is among the most frequently mentioned species, ahead of other raptors and carnivorous mammals; mainly

livestock in the Puna ecosystem.

The Colombian Symposium of Ecology and Conservation of Raptors, Owls and New World Vultures, 3-7 th $^{\text {th }}$ Dec 2018 took take place at the V Congreso Colombiano de Zoología in Bogota. It featured new reports of Andean Condors attacking newborn livestock in Colombia (Los Nevados National Natura Park) plus already known cases in Argentina, Chile, Peru and Ecuador. This situation will sound more conservation alarm bells and means innovative solutions are urgently needed for overcoming this human-wildlife conflict.

Finally, 'A three decade review of telemetry studies on vultures and condors' published in Movement Ecology includes significant information from South America and around the world.

Let us know if you receive this newsletter indirectly and wish to be added to the circulation list. Do send items for inclusion ahead of the next edition in February. Or submit longer articles to the editor of the VSG journal, Vulture News. Reminder that Vulture News including back copies is available free online - do read it!

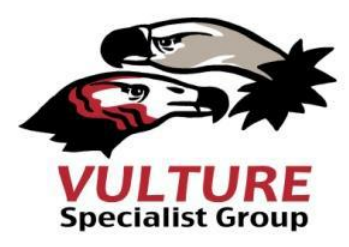

Chris Bowden Andre Botha Co-chairs: Vulture Specialist Group, IUCN Species Survival Commission

Editor \& Asia: Chris Bowden

African Regional Co-chair: Darcy Ogada

European Regional Co-chair: José Tavares

America Regional Co-chairs : North America: Keith Bildstein Latin America: Sergio Lambertucci

Additional contributions: Samuel Bakari, Imad Cherkaoui, Glyn Maude, Roller Ma Ming, Stoyan Nikolov, Emilian Stoynov.

Editor Vulture News: Campbell Murn

VSG Admin Assistant: Lesley Jerome 